\title{
Descolamento Religioso: Tentativa de Ressignificação no Romance Um Defeito de Cor $^{1}$
}

\author{
Religious Displacement: A Reframing Attempted in the Novel Um Defeito de Cor
}

\author{
Cristina Vasconcelos Machado \\ Universidade Federal de Juiz de Fora \\ cleucris@ig.com.br \\ Enilce do Carmo Albergaria Rocha \\ Universidade Federal de Juiz de Fora \\ enilcejf@terra.com.br
}

\section{Resumo}

O presente texto tem por objetivo apresentar uma leitura do trânsito religioso articulado pela personagem-narradora Kehinde no romance 'Um defeito de cor', de Ana Maria Gonçalves. Em terras brasileiras, Kehinde resistirá ferrenhamente à assimilação católica, pois, veladamente, continuará a exercer seus rituais de sua religião africana que a acompanhou pelo Atlântico, e que, posteriormente, transmutar-se-á em uma das manifestações religiosas afro-brasileiras. Todavia, quando Kehinde retornará a África passará a professar a fé Católica. Mas por quê? Porque deixará de praticar a 'religião' de resistência? $\mathrm{Na}$ tentativa de responder a essas perguntas desenvolvemos a leitura desse trânsito religioso como uma tentativa de (re)construção da identidade cultural religiosa da personagem.

Palavras - chaves: Identidade cultural; religiosidade; diáspora

\begin{abstract}
This paper aims to present a reading of the religious traffic articulated by the narrator-character Kehinde, in the novel 'Um defeito de cor', by Ana Maria Gonçalves. In Brazilian lands, Kehinde will resist to the Catholic assimilation, since she covertly continue to practice the rituals of the African religion that had accompanied her across the Atlantic, which will later be transmuted in the African-Brazilian religions. However, when Kehinde returns to Africa, she will profess the Catholic faith. But why? Why she renounces to practice the 'religion' of resistance? In an attempt to answer these questions we developed a reading of this religious traffic as an attempt of (re)construction of the religious cultural identity of the character.
\end{abstract}

Keywords: Cultural identity; religiousness; diaspora. 
A colonização efetiva do Brasil começa a partir de 1530 com a chegada dos primeiros colonos que adotam como principal atividade econômica, além da extração do pau-brasil, a plantação da cana de açúcar. Essa atividade obteve excelentes resultados em solo brasileiro, devido ao clima favorável e à adequação imediata ao solo; e porque Portugal já havia adquirido experiência com essa produção nas ilhas da Madeira e dos Açores.

Os índios não suportavam o trabalho nos engenhos, não estavam acostumados com a atividade agrícola em larga escala, não se adaptaram ao trabalho compulsório, e, consequentemente, fugiam sempre, já que conheciam muito bem o território. Para resolver esse problema, os portugueses recorreram à mão de obra escrava africana: esse trabalhador possuía resistência física e conhecia as práticas da agricultura, e da extração de minérios. Assim, além de resolver o problema da mão de obra em terras brasileiras, a escravidão permitiu à Coroa Portuguesa o desenvolvimento de uma nova atividade econômica, pois o tráfico de escravos era muito lucrativo para a metrópole. Até 1661, os portugueses não podiam comercializar escravos livremente, já que havia um acordo nesse sentido firmado com os holandeses desde a expulsão destes de Pernambuco, em 1654. Somente em 1771 os portugueses obtiveram a 'livre concorrência', aumentando assim os lucros para a Coroa Portuguesa, e o número de escravos transladados que eram comprados graças ao comércio do tabaco e da cana cultivados no território brasileiro por outros escravos. O Brasil recebeu escravos de várias localidades: da Guiné, na segunda metade do século XVI; de Angola e do Congo, no século XVII; da Costa da Mina, no século XVIII; e da Baía do Benim, de 1770 a 1850 :

Nos primeiros séculos do tráfico, chegaram ao Brasil preferencialmente africanos Bantos, seguidos mais tarde pelos sudaneses, cujo tráfico se acentuou a partir da queda do império de Oió, destruídos pelos fons do Daomé e depois dominados pelos haussás. Sem proteção militar, as diferentes populações iorubás passaram a ser presas fáceis do mercado local de escravos mantido por vizinhos de outras etnias (PRANDI, 2000, p.53).

Para atingir o objetivo central do tráfico de escravos - lucro e produtividade - era preciso subjugar os povos africanos. Essa subjugação, iniciada em solo africano, persistiu durante todo o processo da colonização deixando marcas históricas e culturais nas culturas das Américas e da África. Os colonizadores separavam as famílias que haviam se constituído em África, as etnias e os grupos sociais organizados, e colocavam juntos os inimigos. $\mathrm{Na}$ visão ibérica, esse processo divisório, reproduzido nas colônias, constituía uma estratégia de redução da possibilidade de um levante por parte dos grupos escravizados. Nas colônias, além da segregação, os colonizadores, que visavam a efetivação da imposição cultural branca sobre a africana, proibiam os escravos de praticarem sua religiosidade, sua língua e demais hábitos culturais; e os grupos escravizados que desobedecessem a essas regras sofriam violência física e psicológica. Dentre as inúmeras práticas de violência psicológica exercida sobre os grupos escravizados destacamos a imposição religiosa como objeto de nosso texto. A frase de Dom João III: 'A principal causa que me levou a povoar o Brasil foi que a gente do Brasil se convertesse à nossa santa fé católica', citada por Hoornaert em seu livro 'A formação do catolicismo brasileiro' (1974) exemplifica o ideário português em sua 'Cruzada' católica. Assim, o espírito guerreiro se impunha pela força contra os inimigos da fé.

O Catolicismo foi a religião predominante no Brasil durante muitos séculos, principalmente no período colonial. Ele direcionava a vida dos habitantes das terras brasileiras e era praticamente impossível se viver no Brasil sem seguir, ou respeitar, os rituais católicos. O Catolicismo que aqui se desenvolveu, segundo Hoornaert, foi um Catolicismo patriarcal, uma religião de Estado, centrada na família e no campo, aliada ao poder do patriarca, senhor de engenho. Esse modelo de catolicismo, graças ao cotidiano da vida doméstica da casa-grande, se desenvolveu em terras brasileiras sem nenhuma interferência de outras instituições religiosas. O sacerdote exercia as funções de um padre-mestre a serviço da casa-grande, usufruindo de proteção e status estabelecidos pelo senhor de engenho que, venerado pelos escravos, abdicava da violência e castigo, deixando essas tarefas para serem executados pelos seus feitores.

O Catolicismo patriarcal nasceu, portanto, do sincretismo entre a religião católica ibérica e o ambiente escravocrata, já que a religião e a miscigenação constituem dois processos de integração social que caracterizaram a colonização ibérica. Esse tipo de catolicismo implantado no Brasil veiculava comportamentos diferenciados face à moral católica ibérica: enquanto os senhores se aproximavam da salvação e da Graça através da prática do assistencialismo, os escravos deviam se conformar à sua condição e praticar a paciência, pois assim sofriam como Cristo havia sofrido. Essa estrutura religiosa

Cristina Vasconcelos Machado e Enilce do Carmo Albergaria Rocha 
exerceu uma função social precisa, pois ao mesmo tempo em que assegurava uma grande estabilidade, impedia a mobilidade entre as camadas sociais.

O Catolicismo era afirmado na vida pública pelas confrarias, irmandades, ordens terceiras e 'Santas Casas de Misericórdia' que abrigavam todas as instituições públicas destinadas à coletividade, de escolas a hospitais. O simbolismo e a fé em torno dos santos (Nossa Senhora dos Navegantes, Nossa Senhora das Dores, Nossa Senhora da Piedade...), que têm seus nomes relacionados aos perigos atravessados pelos portugueses durante as viagens marítimas, foram utilizados para a efetivação do Catolicismo:

No período colonial, marcado pela fé na providência, as imagens dos santos eram realmente imagens do Brasil, elas nos revelam a verdade a respeito do Brasil. O simbolismo religioso diz respeito a experiências humanas concretas, ele fornece material para interpretar a vida dos antepassados. A empresa colonizadora ultramarina comportava numerosos perigos: perigos do mar, da terra desconhecida e, sobretudo dos índios (HOORNAERT, 1975, p.45).

Por outro lado, a Santa Inquisição, com sua ferrenha perseguição aos não católicos, garantia a homogeneidade na luta contra índios e negros dando suporte ao colonialismo. Dentro desse cenário sociopolítico aportará no Brasil um navio trazendo Kehinde, a personagem-narradora do romance 'Um defeito de cor', de Ana Maria Gonçalves. O romance apresenta a narrativa memorialística de Kehinde que foi capturada pelos traficantes de escravos, junto com sua irmã gêmea Taiwo, em Uidá, reino do Daomé, no ano de 1817. Após a captura das irmãs gêmeas, a avó se ofereceu para embarcar com suas netas, e na travessia do Atlântico, devido às más condições da viagem, às epidemias, e ao sofrimento infligido aos africanos transladados, ela e sua neta Taiwo faleceram. Entretanto, como ainda não havia iniciado Kehinde aos cultos religiosos praticados pelo povo iorubá, habitantes do reino do Daomé ${ }^{2}$, antes de deixar o mundo dos vivos, a avó chamou-a, e apresentou-lhe alguns rituais iorubás:

(...) a minha avó disse que estava se sentindo fraca e cansada, que perdia a força e a coragem longe dos seus voduns, pois tinha abandonado a terra deles, o lugar em que eles tinham escolhido para viver e onde eram poderosos, e eles não tinham como segui-la. Durante dois dias ela me falou sobre os voduns, os nomes que podia dizer as histórias, a importância de cultuar e respeitar os nossos antepassados (GONÇALVES, 2007, p.61).

Kehinde chegou, portanto, sozinha ao mercado de escravos, no litoral baiano, aonde virá a ser comprada para ser dama de companhia da filha do Sinhô José Carlos e, é nessa fazenda que a narradora vivenciará a experiência traumática da escravidão. Kehinde desembarcou em terras brasileiras determinada a honrar seus voduns e a praticar seus cultos; queria também providenciar o amuleto com a imagem de sua irmã gêmea, já que os iorubás acreditam que os irmãos gêmeos dividem a mesma alma:

$\mathrm{Eu}$, assim que desse, também teria que mandar fazer um pingente que representasse a Taiwo e trazê-lo sempre comigo, de preferência pendurado no pescoço. Eu e a Taiwo tínhamos nascido com a mesma alma e eu precisava dela sempre por perto para continuar tendo a alma por inteiro. Depois da morte dela, o único jeito de isso acontecer é por meio da imagem em um pingente benzido por quem sabe o que está fazendo (GONÇALVES, 2007, p.60).

Os escravos recém-chegados ao Brasil eram batizados antes de pisar na nova terra. Kehinde se deparou assim com o primeiro ritual de imposição cultural religiosa do mundo ibérico:

(...) disseram que antes teríamos que esperar um padre que viria nos batizar, para que não pisássemos em terras do Brasil como alma pagã. (...) Em terras do Brasil, eles tanto deveriam usar os nomes novos, de brancos, como louvar os deuses dos brancos" (GONÇALVES, 2007, p.63).

Kehinde possuía profundos laços com a terra mãe e praticou então, o seu primeiro ato de resistência à aculturação jogando-se nas águas do Atlântico, escapando, assim, ao ritual do batismo: "Ir para a ilha e fugir do padre era exatamente o que eu queria: desembarcar usando meu nome, o nome que a minha avó e a minha mãe tinham me dado e com o qual me apresentaram aos orixás e aos voduns" (GONÇALVES, 2007, p.63).

Durante o tempo que residira na Fazenda do Amparo, no Recôncavo Bahiano, Kehinde conhecera uma ex-escrava, Nega Florinda que a presenteara com

Cristina Vasconcelos Machado e Enilce do Carmo Albergaria Rocha 
seus primeiros orixás/voduns em terras brasileiras. Devido a essa amizade, Kehinde viajou até ao estado do Maranhão e, uma vez lá, nos narra a fundação de um terreiro da religião afro que, segundo a descrição apresentada na narrativa, trata-se de um terreiro de Candomblé ${ }^{3}$ conhecido até os dias atuais como 'Casa das Minas'. Foi nesse terreiro que Kehinde iniciou os ensinamentos para tornar-se uma vodúnsi.

$\mathrm{Na}$ narrativa são descritas outras estratégias de resistência à imposição religiosa elaboradas pelos negros escravos. Dentre elas destacamos:

- $O$ culto às escondidas de seus orixás/voduns:

Nega Florinda apareceu e, sem dizer nada além de um breve cumprimento, foi embora depois de me entregar um embrulho com o pingente que todo ibêji que sobrevive à morte do outro deve usar para conservar a sua alma, e mais uma pequena escultura, também em madeira, representando os dois ibêjis juntos (GONÇALVES, 2007, p.99).

- A correlação de seus voduns/orixás com os santos católicos:

"São Benedito, que era preto como nós, ou Nossa Senhora da Conceição, que se reza como Iemanjá, assim como São Jorge é Xangô e Santo Antônio é Ogum, ou São Cosme e São Damião, que são os Ibêjis" (GONÇALVES, 2007, p. 90).

- A simulação: fingiam adorar os santos dos brancos para escaparem à repressão: "Os que sabiam rezaram; os que não sabiam, movimentaram a boca dizendo qualquer coisa, com medo de reprimenda e para que aquilo acabasse o mais rápido possível" (GONÇALVES, 2007, p.141).

A política cultural, social e racial do Brasil do século XIX empenhou-se em 'obrigar' os negros escravos e os indígenas a adotar os hábitos culturais europeus, principalmente a religião. Entretanto, Kehinde, durante o período de permanência em território brasileiro resistiu ferrenhamente à evangelização católica, mantendo viva a tradição religiosa que a identificava como mulher africana, iorubá, praticante da religião dos voduns. Para isso, precisou atingir uma certa autonomia financeira em território brasileiro, e o conseguiu quando se tornou escrava de ganho nas ruas de Salvador. Esse fato foi determinante na vida da personagem-narradora, visto que lhe permitiu uma certa liberdade de circulação pelas ruas da cidade, bem como economizar o dinheiro suficiente para comprar a sua liberdade. As mulheres na África possuíam uma certa autonomia em relação ao comércio e ao trânsito econômico e, em vista disso, muitas delas haviam acumulado verdadeiras fortunas. No Brasil, quando as negras escravas começaram a ganhar as ruas como escravas de ganho, puderam adquirir suas alforrias, participar de confrarias, visitar babalaôs, articular batuques e cerimônias para os orixás, dentre outras atividades:

(...) à medida que (as mulheres) circulavam pela cidade, faziam circular também notícias, informações, músicas, orações... recriando, no Brasil, o papel feminino de mediadoras de bens simbólicos; porém, mais do que isso, articulando escravos e libertos da alienação promovida pelo sistema escravagista (BERNARDO, 2003, p.44).

Graças à compra de sua liberdade Kehinde pode resistir de forma menos velada à imposição católica. Frequentava o sítio de um babalaô, e sempre fazia oferendas aos seus orixás; da mesma forma, quando foi residir em sua própria casa, determinou a construção de um quarto para os orixás, viajando logo a seguir para o Maranhão, a fim de conhecer a Casa das Minas, onde se iniciou como sacerdotisa Geledé. Dessa maneira, em terras brasileiras, a todo o momento Kehinde, personagem e narradora, afirmou sua religiosidade afro-brasileira. A autonomia da mulher escrava em solo brasileiro explica o porquê de existirem nos atuais terreiros de Candomblé, um longo histórico da presença e liderança das mães de santo. $\mathrm{Na}$ verdade, os negros escravos não tiveram uma participação efetiva na fundação do Candomblé do Brasil, pois permaneceram no campo e não conseguiram, portanto, comprar sua carta de alforria. Sendo assim, não possuíam autonomia para circular livremente, contrariamente às mulheres que, em sua grande maioria, migraram para as cidades.

A luta de Kehinde para manter uma identidade religiosa que a vinculasse à África - mãe e aos seus ancestrais se configura como uma estratégia de sobrevivência e de resistência ao sistema escravocrata, como bem explica Joaquim:

A religião sempre foi uma maneira de povos oprimidos articularem seus movimentos defensivos à dominação. (...) No caso do Brasil, o candomblé surgiu historicamente como foco de resistência religiosa e cultural das populações negras para preservarem

Cristina Vasconcelos Machado e Enilce do Carmo Albergaria Rocha 
suas tradições e os elementos fundamentais de seu conjunto de crenças (...) o candomblé foi um dos principais focos de resistência do negro na sociedade brasileira (JOAQUIM, 2001, p. 13 e 35$)$.

Gostaríamos de ressaltar que o romance 'Um defeito de cor' demonstra a narrativa da escravidão do ponto de vista de uma mulher escrava, que se torna escrava de ganho, e, enfim, liberta. Pela voz de Kehinde, podemos acompanhar a luta de algumas poucas mulheres negras do século XIX que tiveram a possibilidade de se insurgirem contra o regime colonial. Além de praticar a resistência religiosa, a personagem Kehinde participou ativamente na articulação da Revolta dos Malês - levante ocorrido em 1835, cujos líderes muçulmanos lutavam contra a condição escrava e a imposição do catolicismo. A repressão à Revolta por parte do aparelho estatal foi imediata e eficiente; e aqueles que sobreviveram a ela foram executados ou deportados para a África. O Levante e a repressão tiveram repercussão em todo o país, desencadeando o aumento da vigilância e da opressão exercida sobre os escravos. Entretanto, apesar da derrota, a Revolta dos Malês representou, simbolicamente, uma vitória porque se tornou um marco histórico que culminou no Brasil do século XIX com a compreensão por parte da sociedade brasileira do necessário debate acerca da escravidão e do tráfico.

Kehinde ou Luísa Gama, em sua trajetória de vida, veio a se casar com o português Alberto, com quem teve um filho que o próprio pai vendeu como escravo. À procura de seu filho, Kehinde percorreu várias partes do território brasileiro, sem, no entanto encontrá-lo. Retornou então, a Salvador, abatida e triste pela perda deste, e devido à morte de vários amigos, companheiros de resistência e luta que haviam sucumbido durante a Revolta dos Malês. De retorno à sua casa, foi submergida por uma saudade imensa da África, e passava seus dias a sonhar com sua família mãe, irmão, irmã e avó - que haviam sido mortos devido à violência instaurada pelo sistema de captura e transporte de africanos para o novo mundo. Decidiu então, retornar à África:

Quase todos os dias eu ia até o cais e ficava sentada em alguma amurada olhando o mar, o movimento dos barcos e das pessoas que chegavam (...). Às vezes, o Tico ia comigo e ficávamos conversando sobre os velhos tempos (...). Muitas vezes falávamos que estaríamos em uma delas (embarcações) a caminho da África (...). Foram tais pensamentos que me levaram aos sonhos, que, por sua vez, me levaram de volta à África (GONÇALVES, 2007, p. 727).

No navio de volta à África, Kehinde conheceu John, um mulato que trabalhava para os ingleses e com quem se relacionou amorosamente. Desembarcou em terras africanas grávida de gêmeos e lá foi acolhida e hospedada na cidade de Uidá, por uma família amiga de sua avó que nunca deixara o território africano. A situação em Uidá era conflituosa devido à presença dos africanos brasileiros, conforme nos narra Kehinde. Por um lado, os retornados sentiam muitas saudades do Brasil e reivindicavam uma identidade cultural brasileira, se considerando como 'civilizados' em relação aos africanos; e por outro, rejeitavam aqueles que nunca haviam saído da África tratando-os de selvagens, o que gerava uma grande hostilidade entre as duas comunidades:

Os brasileiros faziam questão de se afastar ainda mais dos selvagens conversando sempre em português e dizendo que não cultuavam mais os deuses dos africanos, que professavam a fé dos brancos, o catolicismo. Gente que, no Brasil, provavelmente tinha orgulho de não se submeter à religião católica e fazia questão de conversa em línguas de África, como forma de dizer que não tinha se submetido aos brancos, mas que, de volta à terra, esses costumes (...)Todos os retornados se achavam melhores e mais inteligentes que os africanos. Quando os africanos chamavam os brasileiros de escravos ou traidores, dizendo que tinham se vendido para os brancos e se tornado um deles, os brasileiros chamavam os africanos de selvagens, de brutos, de atrasados e pagão (GONÇALVES, 2007, p.756, 757).

Kehinde sonhara em retornar à África, mas àquela África de 1817, cujas marcas estavam em sua memória, e reencontrou a cidade de Uidá em um momento culturalmente conturbado devido às discordâncias entre africanos e retornados. A África da imaginação de Kehinde não existia, ou talvez nunca existirá, uma vez que o que ela guardava em suas memórias eram suas impressões da infância. Kehinde também já não era mais a mesma, pois cerca de trinta anos já haviam se passado, e essa distância temporal e cultural gerara na personagem-narradora um estranhamento familiar:

Era estranho ver mulheres com o peito de 
fora, e senti um pouco de vergonha por estar olhando para elas, que também olhavam para mim quase com o mesmo espanto. Com certeza já tinham visto muitas mulheres usando vestidos como o meu, como os que se usava no Brasil, mas não na casa delas (...) achei que estava estranhando a comida, que eu fazia grande esforço para comer com as mãos, pois não havia talheres (GONÇALVES, 2007, p. 745, 748).

Os fragmentos acima demonstram as primeiras impressões de Kehinde e de suas amigas durante os primeiros dias de retornadas ao se confrontarem com hábitos tão diversos dos seus. Kehinde passará então, a viver em África sentindo-se fragmentada devido às saudades do Brasil. E para compensar essa saudade tudo aquilo de que ela precisa, ou seja, móveis, roupas, alimentos, e mesmo o estilo arquitetônico para a construção de sua casa, será 'importado' das terras brasileiras. "(...) percebi que não era somente porque os retornados tinham mais dinheiro; o que eles tinham mesmo era saudade, e as coisas da Bahia faziam com que recordassem o tempo vivido lá (GONÇALVES, 2007, p.750)."

Com o correr do tempo, Kehinde observará suas próprias contradições, fragmentações e dicotomias identificando-as àquelas vividas pelos outros retornados. Assim, por exemplo, a questão dos nomes quando do nascimento de seus filhos gêmeos em território africano:

Mas eu não queria dar nomes africanos para meus filhos, pois gostava mais dos nomes brasileiros, achava bonito o modo de dizer. Isso também contradizia o que eu pensava antes, quando não quis ser batizada para conservar meu nome africano, usando o nome brasileiro somente quando me convinha (GONÇALVES, 2007, p. 766767).

A personagem deverá, portanto, vivenciar novamente em solo africano um processo de (re)construção cultural. Todos os elementos culturais assimilados no Brasil, e que ela renegara em terras brasileiras, são aqueles que a identificarão como africana retornada, principalmente no que diz respeito à religião. E terá a compreensão de que participa de um duplo pertencimento identitário, sendo suas contradições fruto das difíceis negociações que a atravessam:

(...) Apesar de ter nascido em África, eu também era considerada brasileira, assim como muito outros que nem tinham vivido no Brasil. (...) bastando que soubessem um pouquinho de português e que, como todos os outros brasileiros falsos ou verdadeiros, se dissessem católicos. Era a religião que unia esse povo todo, mesmo que não houvesse igreja para frequentar, mesmo que o forte passasse muito tempo sem a presença de um padre. (...) Os retornados mais antigos diziam que éramos o novo povo africano, que formaríamos um novo país dentro da África, porque éramos da África e do Brasil, uma imensa família que não tinha nem tribo nem rei (GONÇALVES, 2007, p. 773).

Kehinde batizará seus filhos gêmeos no Catolicismo e lhes dará nomes brasileiros: "Maria Clara, em homenagem à sinhazinha, (...) e João, em homenagem ao John, e também ao padre Heinz." (GONÇALVES, 2007, p.767). Assumirá o seu nome cristão, Luísa; participará na organização de manifestações religiosas católicas, mas não deixará de cultuar seus orixás; e importará produtos para sua casa vindos do Brasil. É curioso observar que o trânsito religioso de Kehinde vai de encontro ao seu deslocamento físico, pois quando está no Brasil deseja manter sua memória africana; e quando está em África, quer manter os vínculos com o Brasil.

Segundo Stuart Hall (2003): "a complexidade da identificação diaspórica interrompe qualquer 'retorno' a histórias originais fechadas e 'centradas' em termos étnicos." (p. 25). Assim, o retorno sonhado pela narradora-personagem tornara-se impossível, já que Kehinde em sua luta pela sobrevivência havia se metamorfoseado, e sua complexidade cultural não cabia mais dentro de uma cultura étnica fechada. $\mathrm{Na}$ situação diaspórica vivida por Kehinde sua identidade cultural tornara-se, no mínimo, dupla. Sendo assim, ela se sentirá sempre como deslocada, conforme nos explica ainda Hall: "Não podemos jamais ir para casa, voltar à cena primária enquanto momento esquecido de nossos começos e 'autenticidade', pois há sempre algo no meio (between)" (p. 27).

Concluindo, pudemos observar através desse estudo que o trânsito e as negociações religiosas da personagem Kehinde constitui um exemplo da fragmentação e do hibridismo cultural dos retornados na tentativa de (re)construir suas identidades culturais dilaceradas no Atlântico negro. Assim, os sentimentos contraditórios causados pelo deslocamento, o estranhamento e a fragmentação vivenciados pela narradora-personagem refletirão, diretamente, em suas

Cristina Vasconcelos Machado e Enilce do Carmo Albergaria Rocha 
negociações de pertencimento e em sua identidade cultural híbrida.

1 As considerações aqui apresentadas são provenientes da pesquisa intitulada "Negociações culturais da diáspora africana do ponto de vista da mulher escrava no Brasil do século XIX", realizada com o apoio financeiro do Conselho Nacional de Desenvolvimento Científico e Tecnológico / CNPq.

2 A língua falada pelo povo do reino de Daomé era o iorubá. Os iorubás tinham como costume religioso a crença em voduns - termo usado para designar as divindades ou forças do mundo espiritual -, e cultuavam seus antepassados mortos. $\mathrm{Na}$ África o culto dos voduns era organizado a partir de uma instituição religiosa complexa: espaços sagrados estáveis dedicados às divindades (templos com altares); um corpo sacerdotal hierarquizado, na maioria, homens no comando; uma coletividade de devotos ou vodúnsis (nome dado às sacerdotisas); uma série de atividades rituais periódicas, envolvendo o transe; culto iniciático e oferendas às divindades.

3 Os africanos transladaram para o novo espaço social do Brasil uma pluralidade de culturas. " $\mathrm{Na}$ forma de memória e de experiências individualizadas os escravos levaram 'fragmentos de cultura', porém desprovidos das instituições sociais que lhes davam expressão.” (PARÉS, 2006, p.109). Assim, para estabelecer uma instituição de caráter "africano" no Brasil, os cativos lançaram mão desses "fragmentos de cultura" que lhes eram próprios, a partir das especificidades de certas tradições religiosas africanas iniciaram o processo de reinstitucionalização/reconstrução de suas religiões.

\section{Referências}

BERNARDO, Teresinha. Negras, mulheres e mães: lembranças de Olga de Alaketu. Rio de Janeiro: Pallas, 2003.

GONÇALVES, Ana Maria. Um defeito de cor. 2.ed. Rio de Janeiro: Record, 2007.

HALL, Stuart. "Pensando a diáspora: reflexões sobe a terra no exterior”. In: __. Da diáspora: identidades e mediações culturais. Belo Horizonte: Editora UFMG, 2003. p.21-33.

"Quando foi o pós-colonial? Pensando no limite". In: Da diáspora: identidades e mediações culturais. Belo Horizonte: Editora UFMG, 2003.

HOORNAERT, Eduardo. Formação do catolicismo brasileiro: 1550 a 1800. Petrópolis: Vozes, 1974.

JOAQUIM, Maria Salete. O papel da liderança feminina na construção da identidade negra. Rio de Janeiro: Pallas, 2001.

PARÉS, Luis Nicolau. A formação do Candomblé: história e ritual da nação jeje na Bahia. São Paulo: Editora da Unicamp, 2006.

PRANDI, Reginaldo. "De africano a afro-brasileiro: etnia, identidade, religião". Revista USP, São Paulo, USP, n.46, p.52-65, jun./ago. 2000.

Cristina Vasconcelos Machado e Enilce do Carmo Albergaria Rocha 